\title{
RESISTENCIA GENÉTICA A LA ENFERMEDAD DE LA CEREZA DEL CAFÉ EN VARIEDADES CULTIVADAS EN COLOMBIA
}

\author{
Carlos Ernesto Maldonado Londoño (D) *, Lucía Ángel Giraldo (iD) **
}

\begin{abstract}
Maldonado, C. E., \& Ángel-Giraldo, L. (2020). Resistencia genética a la Enfermedad de la Cereza del Café en variedades cultivadas en Colombia. Revista Cenicafé, 71(1), 68-90. https://doi.org/10.38141/10778/1121
\end{abstract}

La enfermedad de las cerezas del café (CBD), antracnosis causada por el hongo Colletotrichum kahawae subsp. kahawae, ha sido registrada solo en África y puede ocasionar pérdidas de producción hasta del $80 \%$. Cenicafé desarrolla variedades resistentes a las enfermedades más limitantes para el cultivo, aún en ausencia de los patógenos en Colombia, usando al Híbrido de Timor (HT) como la principal fuente de resistencia a la roya del cafeto y a CBD. El propósito de este estudio fue conocer la presencia del gen $C k-1$ de resistencia a CBD en las principales variedades de café cultivadas en Colombia, establecer la correlación entre la presencia de $C k-1$ y la respuesta a inoculación de hipocótilos y explorar las bases genómicas de la resistencia. Los marcadores moleculares ligados a $C k-1$ se ubicaron en el cromosoma 1 de Coffea canephora, región genómica con quince genes de resistencia a enfermedades. Se encontraron marcadores para $C k-1$ en todas las líneas mejoradas derivadas del HT-1343 y ausentes en las variedades Típica, Borbón y Caturra, y en líneas derivadas del HT-832/1. No hubo correlación entre las formas alélicas de resistencia a CBD y la resistencia medida por inoculación de hipocótilos. La alta frecuencia de formas alélicas asociadas con resistencia a $\mathrm{CBD}$ en materiales seleccionados por resistencia a roya sugiere cosegregación de genes de resistencia para ambas enfermedades. La estrategia de variedades multilínea desarrolladas por Cenicafé, que actualmente corresponde a cerca del $80 \%$ del café sembrado en el país, hace que la población en general esté protegida ante la eventual llegada del patógeno a Colombia.

Palabras clave: Coffea arabica, Coffea canephora, Colletotrichum kahawe subsp. kahawae, genes de resistencia a enfermedades, marcadores moleculares, genómica comparativa.

\section{GENETIC RESISTANCE TO COFFEE BERRY DISEASE ON COFFEE VARIETIES CULTIVATED IN COLOMBIA}

Coffee Berry disease (CDB), an anthracnose caused by the fungus Colletotrichum kahawae subsp. Kahawae, has been registered only in Africa and it can cause up to $80 \%$ of crop losses. Cenicafé works on the development of varieties resistant to the main coffee diseases, even in absence of the pathogens in Colombia; such studies use Timor Hybrid (HT) as the main source of resistance against coffee leaf rust (CLR) and CBD. The objective of this study was to screen the presence of the $C k-1$ gene, resistant to $\mathrm{CBD}$, on the main coffee varieties cultivated in Colombia in order to establish the correlation between the presence of $C k-1$ and the response to hypocotyl inoculation, and to explore the genomic basis of the resistance. Molecular markers linked to $C k-1$ were located at the Coffea canephora chromosome 1 , a genomic region with fifteen disease resistance genes. Markers for $C k-1$ were found in all the breeding lines derived from TH-1343 and absent in Typica, Bourbon, and Caturra varieties and in lines derived from TH-832/1. There was no correlation between the allelic forms of $\mathrm{CBD}$ resistance and the resistance of the genotype measured by the hypocotyl inoculation test. The high frequency of allelic forms associated with CDB resistance in materials selected mainly for CLR resistance suggests co-segregation of resistance genes for both diseases. The strategy of multi-line varieties developed by Cenicafé, which currently corresponds to $80 \%$ of the coffee planted in Colombia, protects the crop population against the eventual arrival of the pathogen in Colombia.

Keywords: Coffea arabica, Coffea canephora, Colletotrichum kahawe subsp. kahawae, disease resistance genes, molecular markers, comparative genomics.

\footnotetext{
* Investigador Científico I. Disciplina de Mejoramiento Genético, Centro Nacional de Investigaciones de Café, Cenicafé. Manizales, Caldas, Colombia. https://orcid.org/0000-0001-9433-6979.

**Asistente de Investigación. Disciplina de Mejoramiento Genético, Centro Nacional de Investigaciones de Café, Cenicafé. Manizales, Caldas, Colombia. https://orcid.org/0000-0002-6403-4977.
} 
La enfermedad de las cerezas del café o CBD (sigla en inglés para Coffee Berry Disease), es una de las enfermedades más limitantes de la producción de café en África. Su agente causal, el hongo Colletotrichum kahawe subsp. kahawae J.M. Waller \& Bridge., produce una antracnosis en flores, frutos en cualquier estado de desarrollo y ocasionalmente hojas (Silva et al., 2006). El daño principal ocurre cuando infecta frutos verdes, produciendo lesiones hundidas, que causan momificación y caída de frutos (Silva et al., 2006) (Figura 1). La enfermedad puede causar pérdidas de producción hasta del $80 \%$, si no es controlada químicamente (Griffiths et al., 1971). Aunque el CBD no se ha registrado en América, de acuerdo a la descripción de las condiciones ambientales de regiones cafeteras afectadas por la enfermedad en África (Van der Vossen \& Walyaro, 2009; Mugo et al., 2012), la zona cafetera colombiana presenta condiciones climáticas favorables para el desarrollo del hongo.

Cenicafé, desde la década de 1970, desarrolla un programa de selección por resistencia a
CBD en ausencia del patógeno, utilizando como fuentes de resistencia el Híbrido de Timor (HT) y Rume Sudan, cruzándolas con la variedad Caturra. El HT es producto de un cruzamiento interespecífico natural entre $C$. arabica y $C$. canephora, y presenta regiones de introgresión que le han conferido resistencia a la roya del cafeto (Hemileia vastatrix), a CBD, Pseudomonas syringae y al nematodo Meloidogyne exigua (Clarindo et al., 2013). Cruzamientos entre C. arabica var. Caturra y el HT-1343 fueron la base para la selección por resistencia a la roya en el que se obtuvieron las variedades compuestas o multilínea de porte bajo tales como, Colombia (Castillo y Moreno, 1988), Castillo ${ }^{\circledR}$ con sus siete componentes regionales (Alvarado et al., 2005a; Alvarado et al., 2005b; Alvarado et al., 2005c; Alvarado et al., 2005d; Alvarado et al., 2006a; Alvarado et al., 2006b; Alvarado et al., 2006c; Posada et al., 2006), Cenicafé 1 (Flórez et al., 2016) y Castillo ${ }^{\circledR}$ Zonales (Flórez et al., 2018). Dos introducciones del HT, 1343 y 832/1, se usaron como fuente de resistencia a la roya en la variedad de porte alto Tabi. La estrategia utilizada por Cenicafé

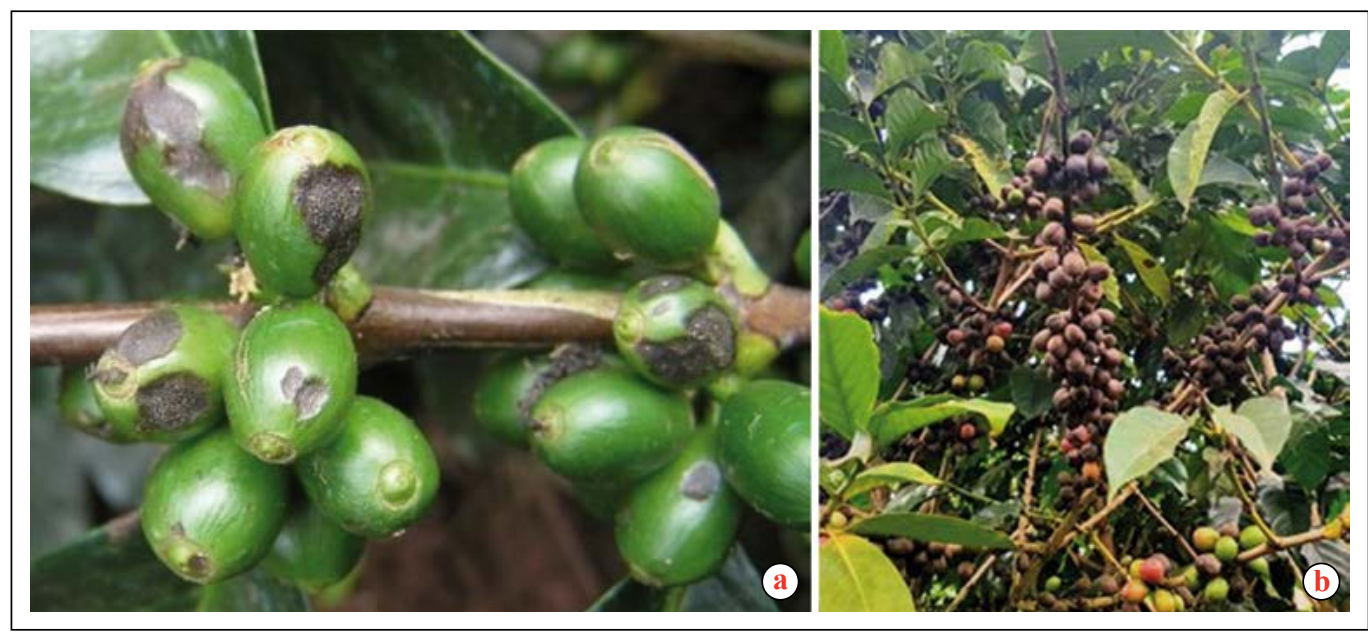

Figura 1. Síntomas de la enfermedad de las cerezas del café-CBD. a. Estados iniciales de infección en frutos en desarrollo (Phiri, 2018); b. Estado avanzado de la enfermedad, frutos momificados (Alworah, 2019). 
para una resistencia durable a la roya se basó en variedades multilínea, donde la diferente distribución de genes de resistencia en cada una de las líneas permitió una diversidad genética dentro del lote, reduciendo la posibilidad de establecimiento de una raza del patógeno capaz de superar la resistencia genética, contrario a lo que ha ocurrido con variedades de café con uniformidad genética o monolíneas.

En ausencia de C. kahawae subsp. kahawae en Colombia se implementó una estrategia de pre-selección de materiales por resistencia a CBD, mediante pruebas de infectividad de hipocótilos, realizadas en los laboratorios del Centro de Investigaciones de la Roya del Café (CIFC) en Portugal. Entre 1997 y el 2015 se realizaron cerca de 6.800 pruebas de inoculación, evaluando cerca de 600 materiales mejorados y otros componentes de la Colección Colombiana de Café (Documento interno Programa de Mejoramiento Genético - Cenicafé).

La selección definitiva de materiales resistentes a enfermedades debe desarrollarse en condiciones de campo, en presencia del patógeno. En Kenia fue producida la variedad Ruiru 11, de porte bajo, resistente a la roya y al CBD (Gichuru, 2007; Omondi et al., 2001), siendo el progenitor que aporta estas características un material desarrollado por Cenicafé (derivado del HT-1343), enviado a Kenia en la década de 1970, para probar su resistencia a la roya. El mismo progenitor ha sido utilizado en programas de mejoramiento del café en Kenia, Tanzania y Zambia (Mtenga et al., 2007; Kilambo et al., 2013a y 2013b; Gichuru, 2007; Omondi et al., 2001; Silva et al., 2006).

La genética de la resistencia a CBD es controversial, para algunos autores la resistencia es oligogénica y para otros poligénica. Van der Vossen y Walyaro $(1980,2009)$ proponen que la resistencia puede explicarse por genes de efecto mayor en tres loci diferentes: el gen dominante $T$ presente en el HT, el gen $R$ de acción dominante presente en las variedades Rume Sudan y Pretoria, y el gen recesivo $k$ que se encuentra en Rume Sudan, K-7 y Pretoria, pero dado el carácter cuantitativo de la resistencia puede haber más genes involucrados (Van der Graaff, 1981).

Hasta el momento solo se ha mapeado un gen de resistencia a CBD y no se conoce la secuencia del gen responsable. Gichuru y colaboradores (2008) evaluaron poblaciones segregantes derivadas del cruzamiento Catimor 88 x SL28 en campos de cultivo con presencia natural del patógeno. El primer progenitor es una línea resistente portadora del locus $\mathrm{T}$ que fue desarrollada en Cenicafé (derivada de HT1343). Los autores encontraron un grupo de ligamiento conformado por ocho marcadores AFLP y dos microsatélites (SSR) fuertemente asociados con el fenotipo resistente a CBD, que contiene el gen principal de resistencia al que llamaron $C k-1$. El marcador SSR SAT235 es el más cercano al gen $C k-1$, ha sido validado en el campo en presencia del patógeno (Gichimu et al., 2014) y usado en selección asistida por marcadores moleculares (SAM) como medida indirecta de la resistencia a CBD (Alkimim et al., 2017).

Contar con marcadores moleculares validados es de gran ayuda para utilizar SAM para la selección de progenies en etapas tempranas de mejoramiento o en progenies avanzadas. Los marcadores de ADN presentan ventajas para la detección del rasgo de interés al no ser afectados por el ambiente, en corto tiempo pueden evaluarse tantos rasgos como marcadores se tengan, sin esperar a la expresión directa del rasgo en un punto fenológico específico de la planta. En un cultivo perenne como el café, el desarrollo de una variedad puede tardar en promedio 25 
años y los marcadores moleculares aplicados en SAM son una herramienta para acelerar el proceso de selección.

El propósito de este estudio fue conocer la presencia del gen $C k-1$ de resistencia a CBD en las principales variedades de café cultivadas en Colombia, establecer la correlación entre la presencia de $C k-1$ y la respuesta a inoculación de hipocótilos, y explorar las bases genómicas de la resistencia.

\section{MATERIALES Y MÉTODOS}

Material vegetal. Se analizaron tres progenitores, en generación $\mathrm{F} 4$ en su mayoría, de los componentes de las variedades multilínea Colombia, Tabi, Castillo ${ }^{\circledR}$ y sus regionales, Cenicafé-1, Castillo ${ }^{\circledR}$ Zonales, además de las variedades tradicionales Típica, Borbón y Caturra, estas últimas susceptibles a la roya del cafeto. También se incluyeron las variedades monolínea Costa Rica 95 y Catimor, desarrolladas en Centro América para resistencia a la roya y que son cultivadas en baja proporción en Colombia. Se utilizaron como control resistente a CBD accesiones del HT-1343 que dieron origen a las variedades desarrolladas por Cenicafé y Caturra como control susceptible. Se recolectaron hojas en crecimiento activo, que correspondían al primer o segundo par de hojas del tercio medio o superior del árbol. Los materiales de estudio son conservados en la Estación Experimental Naranjal de Cenicafé, ubicada en el municipio de Chinchiná (Caldas, Colombia). También se recolectó tejido de cuatro plantas de Catimor, en un cultivo comercial en el Departamento de Risaralda.

Extracción DNA. El tejido foliar se congeló a $-80^{\circ} \mathrm{C}$ y se deshidrató al vacío en un liofilizador (Labconco, FreeZone 6 L). El material deshidratado se maceró hasta obtener un polvo fino y el ADN se extrajo por el método de CTAB modificado para café, así: cerca de $80 \mathrm{mg}$ de tejido foliar deshidratado y macerado se suspendió en 500 $\mu \mathrm{L}$ de buffer CTAB $2 \mathrm{X}$ precalentado a $65^{\circ} \mathrm{C}$ (CTAB 2\% P/V, Tris 0,1 M, EDTA $0,02 \mathrm{M}$, $\mathrm{NaCl} 8,2 \% \mathrm{P} / \mathrm{V}$, polivinilpirrolidona $2 \% \mathrm{P} / \mathrm{V}$ y B-mercaptoetanol 1,5\% V/V). La muestra se incubó a $65^{\circ} \mathrm{C}$ durante 30 minutos, agitando regularmente. Posteriormente se añadió un volumen de cloroformo:alcohol-isoamílico (24:1) y se recuperó la fase acuosa después de centrifugar la mezcla a $4^{\circ} \mathrm{C}$, durante 15 minutos a $14.000 \mathrm{rpm}$. El ADN se precipitó llevando la solución a una concentración 0,18 $\mathrm{M}$ de acetato de sodio y $0,7 \mathrm{M}$ de $\mathrm{NaCl}$ y adicionando un volumen de alcohol isopropílico. El precipitado se lavó con etanol al 70\% y se resuspendió en $100 \mu \mathrm{L}$ de agua ultrapura, a la cual se adicionaron $2,5 \mu \mathrm{g}$ RNasa-A y se incubó a $37^{\circ} \mathrm{C}$ por 30 minutos, seguido de una nueva precipitación. Las muestras se dejaron en resuspensión a $4^{\circ} \mathrm{C}$ durante $48 \mathrm{~h}$. La cantidad y calidad del ADN extraído se evaluó por medio de electroforesis cuantitativa en geles de agarosa al 1,2\% en buffer TAE, con el uso de la escalera de peso molecular Low Mass Ladder (Invitrogen) y por espectrofotometría en un NanoDrop 2 (Thermo-Fisher) con al menos dos repeticiones por muestra.

\section{Amplificación y evaluación de marcadores} moleculares. Se genotipificó un subgrupo de los materiales de estudio mediante la amplificación por PCR de los marcadores microsatélite SAT207, FR34-6CTG y SAT235. El marcador FR34-6CTG amplifica el mismo locus que SAT207 produciendo amplicones de menor tamaño y fue reportado por Guzmán y Moncada (2012). Las secuencias de los oligonucleótidos cebadores se presentan en la Tabla 1. La mezcla de PCR contenía 80 ng de ADN, 0,5 $\mu \mathrm{M}$ de cada cebador, 0,125 mM de cada dNTP, buffer de PCR 1X, 1,5 $\mathrm{mM}$ de $\mathrm{MgCl}$ y una unidad de Taq polimerasa en un volumen de $25 \mu \mathrm{L}$. Las condiciones 
del programa de PCR fueron iguales a las publicadas por Guzmán y Moncada (2012), empleando el método "touchdown PCR": $94^{\circ} \mathrm{C}$ por $5 \mathrm{~min}$, seguido de cinco ciclos con alineamiento de cebadores de $1 \mathrm{~min}$, bajando $1^{\circ} \mathrm{C}$ en cada ciclo, desde $60^{\circ} \mathrm{C}$ a $55^{\circ} \mathrm{C}$, con un paso previo de denaturación de $94^{\circ} \mathrm{C}$ de 1 min y uno posterior de extensión de $72^{\circ} \mathrm{C}$ por $1 \mathrm{~min}$. Se continuó con 35 ciclos de $94^{\circ} \mathrm{C}$ por $1 \mathrm{~min}, 55^{\circ} \mathrm{C}$ por $1 \mathrm{~min}, 72^{\circ} \mathrm{C}$ por $1 \mathrm{~min} \mathrm{y}$ finalizando con $72^{\circ} \mathrm{C}$ por $5 \mathrm{~min}$. Los fragmentos amplificados se corrieron en geles verticales desnaturalizantes de poliacrilamida al $6 \%$, $7 \mathrm{M}$ de urea y TBE $0,7 \mathrm{X}$ y se tiñeron con nitrato de plata. El subgrupo fue usado para el desarrollo de pruebas preliminares y se continuó la evaluación del total de las muestras con los marcadores SAT235 y FR34-6CTG.

Análisis bioinformático. Por medio de PCR electrónica (ePCR) (Schuler, 1997) sobre el genoma de $C$. canephora (Denoeud et al., 2014) se determinó in silico el número de copias, la posición genómica y las formas de los alelos amplificados. Adicionalmente, se buscaron genes de resistencia en la región mapeada al integrar el grupo de ligamiento que contiene el gen $C k-1$ (Gichuru et al., 2008) y el genoma de $C$. canephora (Denoeud et al., 2014) con el archivo de anotación disponible en la base de datos Coffee Genome Hub (http:// coffee-genome.org/) creada por el Instituto
Nacional Francés de Investigaciones para el Desarrollo - IRD y el Centro de Cooperación Internacional en Investigación Agronómica de Francia - CIRAD.

Relación fenotipo y genotipo. Se reunió la información de las pruebas de infectividad llevadas a cabo en la CIFC entre 1997 y 2015. Se encontraron registros de cerca de 6.800 pruebas de inoculación, evaluando alrededor de 600 materiales mejorados y otros componentes de la Colección Colombiana de Café, con 12 aislamientos de C. kahawae subsp. kahawae (Documento interno Programa de Mejoramiento Genético-Cenicafé, consolidando información de investigaciones lideradas por Germán Moreno y Pilar Moncada). Se analizaron nueve aislamientos probados en al menos cinco componentes de la variedad Castillo ${ }^{\circledR}$. Los aislamientos incluidos provenían de Camerún (aislamientos $\mathrm{C}$ y $\mathrm{CA}$ ), Mozambique (M), Kenia (Q, Q2), Zimbabue (Z, Z1 y Z9) y un aislamiento de Ruanda (R). La evaluación de infectividad se realizó mediante el método de Cook y Van der Vossen (1973) modificado por Van der Graff(1981), donde 100 semillas de una misma planta se sembraron en arena estéril, cuando las plántulas iniciaron la apertura de hojas cotiledonares se inocularon con una suspensión de $2 \times 10^{6}$ conidias $/ \mathrm{mL}$ y se mantuvieron bajo una humedad relativa del $100 \%$, pasadas 48 horas se repitió la inoculación y se dejaron 48 horas más, en un ambiente

Tabla 1. Secuencia de los cebadores de los marcadores moleculares tipo microsatélite (SSR) asociados con el gen $C k-1$ de resistencia a CBD proveniente del Híbrido de Timor.

\begin{tabular}{ccccc}
\hline Primer ID & Primer-F 5'-3' & & Primer-R 5'-3' & Referencia \\
\cline { 5 - 6 } SAT207 & GAAGCCGTTTCAAGCC & & CAATCTCTTTCCGATGCTCT & $\begin{array}{c}\text { Gichuru et } \\
\text { al., 2008 }\end{array}$ \\
FR34- & AAGCCGTTTCAAGCCATA & & GCTTCTGTCTCAACACAACA & $\begin{array}{c}\text { Guzman y } \\
\text { Moncada, } \\
\text { SCTG }\end{array}$ \\
SAT235 & TCGTTCTGTCATTAAATCGTCAA & GCAAATCATGAAAATAGTTGGTG & $\begin{array}{c}\text { Gichuru et } \\
\text { al., 2008 }\end{array}$ \\
\hline
\end{tabular}


con humedad relativa del $100 \%$. Después de tres semanas se evaluó la infección usando en una escala de cuatro niveles. Se consideró que un material era resistente si el 50\% o más de los individuos evaluados se encontraban en los niveles 1 y 2 que corresponden a los de menor daño por el patógeno, o eran susceptibles si el $50 \%$ o más de los individuos mostraban daños con nivel 3 o 4 . Para cada marcador molecular y aislamiento se construyó una matriz de contingencia para análisis de correlación de datos binarios (presencia ausencia del marcador y de la resistencia) mediante la prueba de correlación Phi.

\section{RESULTADOS Y DISCUSIÓN}

\section{Pruebas de amplificación de los microsatélites y análisis bioinformático}

Las evaluaciones de los marcadores SAT207 y FR34-6CTG, considerados idénticos por Guzmán y Moncada (2012), mostraron diferencias en el tamaño y número de bandas de los amplicones. Aunque ambos marcadores amplifican parte de un mismo locus, el tamaño de los fragmentos amplificados para del marcador FR34-6CTG y las diferencias entre sus formas alélicas facilitaron su evaluación. La ePCR sobre el genoma de C. canephora (Denoeud et al., 2014) mostró que el sitio de inicio de la amplificación tuvo una diferencia de una base y se presentó una diferencia de tamaño de $86 \mathrm{pb}$ entre ambos marcadores (Tabla 2). El tamaño de los amplicones obtenidos por ePCR fue comparable a los tamaños observados mediante electroforesis en geles de acrilamida (Figura 2). Las diferencias de tamaño entre las formas alélicas asociadas con resistencia y susceptibilidad del marcador SAT235 permitieron que los amplicones pudieran ser evaluados mediante electroforesis en geles de agarosa, agilizando la genotipificación de los materiales y haciendo de este marcador una buena herramienta para SAM, siendo además este marcador el más cercano al gen $C k-1$ (Gichuru et al., 2008).

De acuerdo con los resultados de mapeo publicados por Gichuru et al. (2008), el gen Ck-1 está asociado con los marcadores SSR SAT207 y SAT235, que están separados por $17,2 \mathrm{cM}$. Al integrar el grupo de ligamiento con el genoma de $C$. canephora, mediante ePCR, estos microsatélites se encuentran en el cromosoma 1, a una distancia física de 6.296.765 pb (Tabla 2, Figura 3). La región con mayor probabilidad de contener el gen $C k-1$ cubre $11 \mathrm{cM}$ e incluye el marcador SAT235 y cinco marcadores AFLP. Los marcadores dominantes, como los AFLP, no permiten ser ubicados sobre la secuencia genómica con la misma precisión que se logra con marcadores codominantes como los microsatélites.

Tabla 2. Ubicación de los marcadores asociados con el gen $C k-1$ amplificados sobre la secuencia genómica de Coffea canephora y producto amplificado mediante PCR electrónica.

\begin{tabular}{|c|c|c|c|c|c|}
\hline Marcador & Cromosoma & Cadena & Inicio & Final & Amplicon (pb) \\
\hline FR34-6CTG & Chr1 & + & 29.996 .789 & 29.996 .964 & 176 \\
\hline SAT207 & Chr1 & + & 29.996 .788 & 29.996 .877 & 90 \\
\hline SAT235 & Chr1 & - & 23.700 .199 & 23.700 .420 & 222 \\
\hline
\end{tabular}




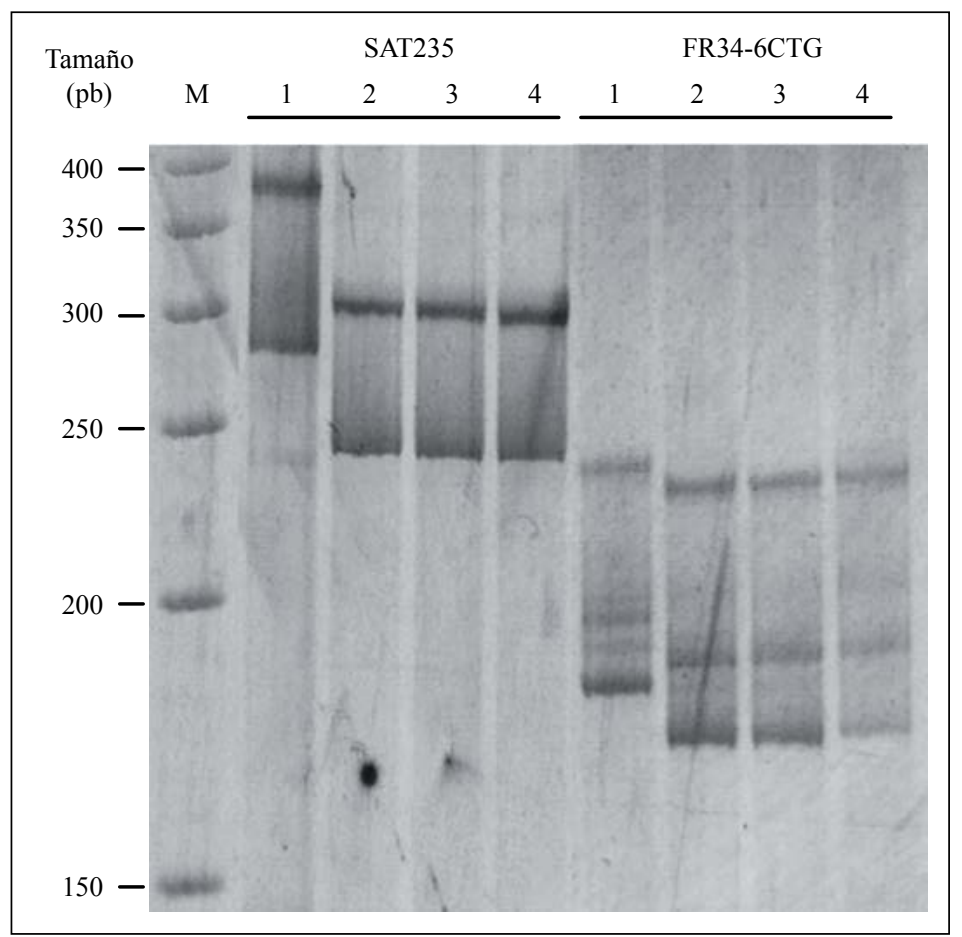

Figura 2. Electroforesis en geles de poliacrilamida al $6 \%$ de los marcadores moleculares asociados con resistencia genética a la enfermedad de las cerezas del café - CBD. Carriles: M) escalera de DNA de $50 \mathrm{pb}, 1)$ variedad Caturra (control susceptible), 2) HT1343-CV1, 3) HT-1343-CV2 (control resistente), 4) Línea componente de la variedad Castillo $^{\circledR}$.
Con el propósito de determinar las coordenadas genómicas en la región que contiene el gen $C k-1$, el cual se extiende corriente abajo del marcador SAT235, y al no contar con distancias físicas conocidas para los marcadores del grupo de ligamiento en esta región, se asumió una improbable relación lineal entre la distancia genética en $\mathrm{cM}$ y la distancia física de los SSRs, donde $1 \mathrm{cM}$ corresponde a $366 \mathrm{~Kb}$ y $\operatorname{los} 10,6 \mathrm{cM}$ a partir de SAT235 comprenderían la región de mayor asociación con el gen $C k-1$ hasta la posición $19,82 \mathrm{Mb}$ del cromosoma $1 \mathrm{de}$ C. canephora (Figura 3 ).

Entre las coordenadas 29,99 Mb y 19,73 $\mathrm{Mb}$ del cromosoma 1 de $C$. canephora se encuentran 612 genes, de acuerdo a los archivos de anotación del genoma (Denoeud et al., 2014). Dentro de ellos se encontraron 15 genes de respuesta de defensa (Tabla 3 ), con término de ontología GO:0006952 (Ashburner et al., 2000; Gene Ontology Consortium, 2019). Estos genes de defensa se encontraron agrupados en dos áreas particulares y tres genes distanciados entre 1,7 y 2,6 Mb (Figura 3). Sobre la región más estrechamente asociada con el gen $C k-1$ se encuentran los genes Cc01_g05220, Cc01_g05230, Cc01_g05240, Cc01_g05270 y Cc01_g05280 ubicados en un grupo de $211,46 \mathrm{~Kb}$, y dos genes apartados Cc01_g05660 y Cc01_g06910, siendo este último el más cercano al marcador SAT235 (Tabla 3, Figura 3).

La información de posición genómica de los marcadores en $C$. canephora concuerda con el mapa genético de $C$. arabica (Moncada et al., 2016) donde el marcador CMA276 (sinónimo de SAT235) se encuentra en el grupo de ligamiento siete. Los análisis de integración entre el mapa genético de C. arabica, 


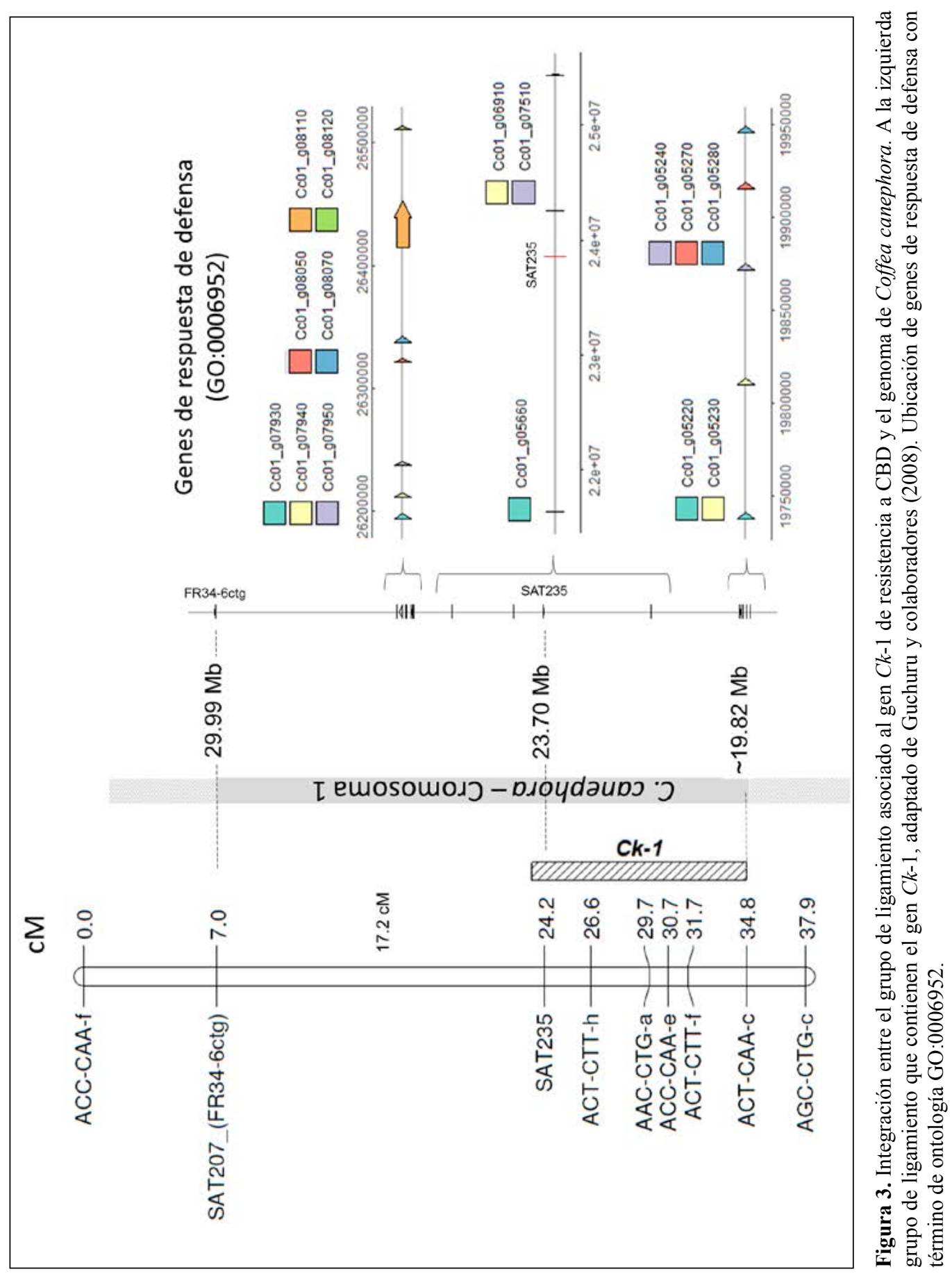


Tabla 3. Genes de resistencia a enfermedades en la región asociada al gen $C k-1$ de resistencia al CBD en el genoma de Coffea canephora. Información extraída del archivo de anotación disponible en el Coffee Genome Hub (http://coffee-genome.org/).

\begin{tabular}{lc}
\hline Nombre del gen & Anotación funcional putativa \\
\cline { 2 - 2 } Cc01_g05220 & Proteína de resistencia a enfermedades RGA3 \\
Cc01_g05230 & Proteína de resistencia a enfermedades RGA3 \\
Cc01_g05240 & Proteína de resistencia a enfermedades RGA3 \\
Cc01_g05270 & Proteína de resistencia a enfermedades RGA2 \\
Cc01_g05280 & Proteína de resistencia a enfermedades RGA2 \\
Cc01_g05660 & Proteína de resistencia a enfermedades RGA1 \\
Cc01_g06910 & Probable proteína de resistencia a enfermedades At5g63020 \\
Cc01_g07510 & Proteína de resistencia a tizón tardío R1-A \\
Cc01_g07930 & Proteína de resistencia a tizón tardío homólogo R1B-14 \\
Cc01_g07940 & Proteína de resistencia a tizón tardío homólogo R1B-23 \\
Cc01_g07950 & Proteína de resistencia a tizón tardío homólogo R1B-14 \\
Cc01_g08050 & Proteína de resistencia a tizón tardío homólogo R1A-6 \\
Cc01_g08070 & Proteína de resistencia a enfermedades (clase CC-NBS-LRR) \\
Cc01_g08110 & Proteína de resistencia a tizón tardío homólogo R1B-14 \\
Cc01_g08120 & Proteína de resistencia a tizón tardío homólogo R1B-14
\end{tabular}

al genoma de $C$. canephora, $C$. arabica y C. eugenioides aportarán información para estudios de genómica funcional del género $\mathrm{y}$ asociación con rasgos de interés, incluyendo resistencia a enfermedades.

La minería de datos en la región asociada al gen $C k-1$ indica la probable presencia de uno o dos grupos de genes de resistencia en el bloque introgresado al HT desde C. canephora, un caso similar se registró para el gen $\mathrm{SH} 3$ de resistencia a la roya del cafeto en una región de introgresión proveniente de $C$. liberica (Lashermes et al., 2010). El agrupamiento de genes de resistencia es común dentro de especies vegetales y han sido reportados en los genomas de arroz, alfalfa, uva y álamo, entre otros (Zhou et al., 2004; Yang et al., 2008). Para delimitar el gen de efecto mayor o aquellos responsables de la resistencia a CBD, si es de naturaleza oligogénica como escenarios posibles de la resistencia (Gichuru et al., 2008), debe saturarse de marcadores moleculares la región de interés y hacer mapeo fino con una población segregante de un alto número de individuos y en presencia de $C$. kahawae subsp. kahawae y H. vastatrix; así la genotipificación de la población segregante y 
su integración con la secuencia genómica de los progenitores de dicha población, sumado a evaluaciones de genes expresados durante procesos infectivos del patógeno en los progenitores y en individuos seleccionados dentro de la población segregante, permitiría acercarse a los genes candidatos de la resistencia y ser validados por métodos de genética reversa.

\section{Amplificación de los marcadores asociados con resistencia a CBD en variedades de café cultivadas en Colombia}

Como resultado de análisis anteriormente descritos se decidió continuar la evaluación sobre los sujetos de estudio con los marcadores FR34-6CTG y SAT235, dando mayor peso a los resultados obtenidos para el marcador SAT235, el más cercano al gen de interés en este estudio (Gichuru et al., 2008).

Los resultados de la amplificación de marcadores moleculares muestran ausencia del bloque de introgresión que contiene el gen $C k-1$ en las variedades tradicionales susceptibles a CBD: Caturra, Típica y Borbón, $\mathrm{y}$ en las variedades provenientes de Centro América: Costa Rica 95 y Catimor. Se encontró variabilidad dentro de los HT evaluados, como fue publicado también por Guzmán y Moncada (2012). En el HT-1343, progenitor de las variedades Colombia, Castillo ${ }^{\circledR}$ y Cenicafé $1, \mathrm{y}$ del 82,6\% de las líneas de la variedad Tabi, se encontraron las formas alélicas de resistencia de los marcadores evaluados, mientras que en el caso del HT 832/1, progenitor de cuatro de los componentes de Tabi, Costa Rica 95 y probablemente del Catimor incluido en el análisis, el bloque de introgresión está ausente, sugiriendo susceptibilidad a CBD en las variedades de Centro América y en el $17,4 \%$ de los componentes de Tabi (Tablas 4 y 11). Para esta última variedad el porcentaje de líneas con progenies susceptibles a CBD es mayor, como se describe más adelante.
Tabla 4. Evaluación de los marcadores asociados con el gen de resistencia $C k-1$ en variedades tradicionales ${ }^{1}$, progenitores de las variedades ${ }^{2}$, Costa Rica 95 y Catimor. La calificación binaria 1 indica la presencia de la forma alélica asociada con resistencia en forma homocigótica, 0 homocigoto para alelo asociado con susceptibilidad y 1/0 la presencia simultánea de las formas alélicas asociadas a resistencia y susceptibilidad (heterocigotos).

\begin{tabular}{ccccc}
\hline Accesión & & SAT235 & & FR34.6CTG \\
\cline { 1 - 1 } Caturra $^{1,2}$ & & 0 & & 0 \\
Typica $^{1}$ & & 0 & & 0 \\
Borbon $^{1}$ & & 0 & & 0 \\
Costa Rica 95 & & 0 & & 0 \\
Catimor & & 0 & & 0 \\
HT-1343-CV1 & & 1 & & 1 \\
HT-1343-CV2 2 & & 1 & & 1 \\
HT-832/1 2 & & 0 & 0 \\
\hline
\end{tabular}

Las líneas componentes de las variedades multilínea evaluadas, corresponden a generaciones F4 y F5, siendo estos los progenitores de las plantas de los lotes de producción de semilla certificada, de tal manera que se entrega a los caficultores semilla de generación F6 y una baja proporción de F7. De esta forma, una porción reducida de la progenie derivada de las líneas evaluadas será susceptible al CBD, por ausencia del gen de resistencia $C k-1$ (Tablas 11 y 12).

Todos los progenitores de las líneas componentes de la variedad Colombia presentaron la forma alélica de resistencia del marcador SAT235, tres de ellos en forma heterocigótica. Dos plantas presentaron ausencia del marcador FR34-6CTG y una de ellas con SAT235 heterocigótico. Lo que indica que el $8,8 \%$ de los progenitores producirían una fracción de su descendencia sin el gen $C k-1$, donde el $96,7 \%$ de las semillas entregadas al agricultor serían resistentes, si existe en la mezcla igual proporción de cada componente 
varietal de la multilínea. Los detalles de la composición y presencia de marcadores para la variedad Colombia se presentan en las Tablas 5 y 11.

Dentro de las líneas componentes de la variedad Tabi, el $26 \%$ presentaron ausencia del bloque de introgresión que contiene el gen $C k-1$ al presentar en forma homocigótica las formas alélicas asociadas con susceptibilidad a CBD para ambos SRRs evaluados. Cuatro componentes más $(17,4 \%)$ fueron homocigóticos para la forma susceptible del marcador (Tabla 6). El $73,9 \%$ de la semilla certificada de esta variedad sería resistente a CBD si hay igual proporción de cada componente varietal de la multilínea (Tabla 11).

Todos los componentes de la variedad Castillo $^{\circledR}$ General y las siete Variedades Castillo $^{\circledR}$ Regionales presentaron al menos un alelo de resistencia para SAT235. FR34-

Tabla 5. Evaluación de los marcadores moleculares asociados con el gen de resistencia $C k-1$ en los componentes de la variedad Colombia. La calificación binaria 1 indica la presencia de la forma alélica asociada con resistencia en forma homocigótica, 0 homocigoto para alelo asociado con susceptibilidad y 1/0 la presencia simultánea de las formas alélicas asociadas a resistencia y susceptibilidad (heterocigotos).

\begin{tabular}{|c|c|c|c|c|c|}
\hline Línea & SAT235 & FR34-6CTG & Línea & SAT235 & FR34-6CTG \\
\hline BH.1247 & 1 & 1 & CU.1991 & 1 & 1 \\
\hline BH.1409 & $1 / 0$ & 1 & CU.1993 & 1 & 1 \\
\hline CU.1778 & 1 & 1 & CU.2021 & 1 & 1 \\
\hline CU.1812 & 1 & 1 & CU.2034 & 1 & 1 \\
\hline CU.1815 & 1 & 1 & CX.2080 & 1 & 1 \\
\hline CU.1819 & 1 & 1 & CX.2375 & 1 & 1 \\
\hline CU.1842 & 1 & 1 & CX.2385 & 1 & 1 \\
\hline CU.1843 & 1 & 1 & CX.2391 & 1 & 1 \\
\hline CU.1849 & 1 & 1 & CX.2583 & 1 & 1 \\
\hline CU.1850 & 1 & 1 & CX.2633 & 1 & 1 \\
\hline CU.1871 & $1 / 0$ & 0 & CX.2708 & 1 & 1 \\
\hline CU.1951 & 1 & 1 & CX.2720 & 1 & 1 \\
\hline CU.1953 & 1 & 1 & CX.2841 & $1 / 0$ & 1 \\
\hline CU.1970 & 1 & 1 & CX.2866 & 1 & 0 \\
\hline CU.1972 & 1 & 1 & DH.18 & 1 & 1 \\
\hline CU.1983 & 1 & 1 & DH.4 & 1 & 1 \\
\hline
\end{tabular}


Tabla 6. Evaluación de los marcadores moleculares asociados con el gen de resistencia $C k-1$ en los componentes de la variedad Tabi. La calificación binaria 1 indica la presencia de la forma alélica asociada con resistencia en forma homocigótica, 0 homocigoto para alelo asociado con susceptibilidad y 1/0 la presencia simultánea de las formas alélicas asociadas a resistencia y susceptibilidad (heterocigotos).

\begin{tabular}{|c|c|c|c|c|c|}
\hline Línea & SAT235 & FR34-6CTG & Línea & SAT235 & FR34-6CTG \\
\hline CJ.154 & 0 & 0 & GA.494 (CJ.38)* & 1 & 0 \\
\hline CJ.212 & 1 & 1 & GB.266 & 1 & 1 \\
\hline CJ.215 & 1 & 1 & GB.306 & 1 & 1 \\
\hline CJ.219 & 1 & 1 & GB.571 & 1 & 0 \\
\hline CJ.220 & 1 & 1 & GB.642 & 1 & 1 \\
\hline CJ.038 & 1 & 0 & GB.682 & 1 & 1 \\
\hline CJ.416 & 1 & 0 & GB.098 & 0 & 0 \\
\hline CJ.582 & 1 & 1 & HG.101 & 0 & 0 \\
\hline CJ.588 & 1 & 1 & HG.132 & 0 & 0 \\
\hline CJ.590 & 1 & 1 & HG.041 & 0 & 0 \\
\hline GA.229 (CJ.581)* & 1 & 1 & HG.089 & 0 & 0 \\
\hline GA.294 (CJ.587)* & 1 & 1 & & & \\
\hline
\end{tabular}

*Línea muerta en la Colección de Germoplasma, se evaluó una línea de igual genealogía.

6CTG fue el marcador que presentó con mayor frecuencia la forma alélica asociada con ausencia del fragmento de introgresión que contiene el gen $C k-1$, para tres de los componentes de Castillo ${ }^{\circledR}$ general y en cinco de los componentes de las Variedades Castillo ${ }^{\circledR}$ Regionales (Tablas 7, 8, 11 y 12). El porcentaje de semilla certificada resistente a CBD, de las Variedades Castillo ${ }^{\circledR}$ liberadas en el 2005 estuvo entre el 87,5\% y el $100 \%$ (Tablas 11 y 12 ).

Entre las variedades liberadas por Cenicafé, entre 2016 y 2018, se encuentra Cenicafe 1 , variedad conformada en su totalidad por líneas portadoras del gen de resistencia $C k-1$, siendo la resistencia a esta enfermedad uno de los criterios de selección de las líneas que la componen (Flórez et al., 2016), solo una de las líneas presenta ausencia del marcador molecular más lejano al gen de resistencia a CBD (Tablas 9 y 11). Las variedades Castillo ${ }^{\circledR}$ Zonales (Flórez et al., 2018), Castillo ${ }^{\circledR}$ Norte y Castillo ${ }^{\circledR}$ Centro, cuentan con dos líneas componentes heterocigóticas para SAT235 y ausencia del marcador FR34-6CTG, mientras que tres líneas componentes de Castillo ${ }^{\circledR}$ Sur muestran este genotipo (Tablas 10 y 11), es decir, que una porción de la progenie del $18,2 \%$ de las componentes de Castillo ${ }^{\circledR}$ Norte y Castillo ${ }^{\circledR}$ Centro y del $27,3 \%$ de los componentes de Castillo ${ }^{\circledR}$ Sur será susceptible al CBD. El porcentaje de semilla certificada de Castillo ${ }^{\circledR}$ Zonales resistente a CBD está entre el $89,7 \%$ y el $93,2 \%$. 
Tabla 7. Evaluación de los marcadores asociados con el gen de resistencia $C k-1$ en los componentes de la variedad Castillo ${ }^{\circledR}$ General. La calificación binaria 1 indica la presencia de la forma alélica asociada con resistencia en forma homocigótica, 0 homocigoto para alelo asociado con susceptibilidad y 1/0 la presencia simultánea de las formas alélicas asociadas a resistencia y susceptibilidad (heterocigotos).

\begin{tabular}{|c|c|c|c|c|c|}
\hline Progenitor & SAT235 & FR34.6CTG & Progenitor & SAT235 & FR34.6CTG \\
\hline ВН.1247 & 1 & 1 & CU.1991 & 1 & 1 \\
\hline BH.1409 & $1 / 0$ & 1 & CU.1993 & 1 & 1 \\
\hline CU.1778 & 1 & 1 & CU.2021 & 1 & 1 \\
\hline CU.1812 & 1 & 1 & CU.2034 & 1 & 1 \\
\hline CU.1815 & 1 & 1 & CX.2065 & 1 & 1 \\
\hline CU.1819 & 1 & 1 & CX.2080 & 1 & 1 \\
\hline CU.1825 & 1 & 1 & CX.2375 & 1 & 1 \\
\hline CU.1842 & 1 & 1 & CX.2385 & 1 & 1 \\
\hline CU.1843 & 1 & 1 & CX.2391 & 1 & 1 \\
\hline CU.1849 & 1 & 1 & CX.2425 & 1 & 0 \\
\hline CU.1850 & 1 & 1 & CX.2583 & 1 & 1 \\
\hline CU.1871 & $1 / 0$ & 0 & CX.2633 & 1 & 1 \\
\hline CU.1911 & $1 / 0$ & 1 & CX.2720 & 1 & 1 \\
\hline CU.1951 & 1 & 1 & CX.2841 & $1 / 0$ & 1 \\
\hline CU.1953 & 1 & 1 & CX.2866 & 1 & 0 \\
\hline CU.1970 & 1 & 1 & DH.18 & 1 & 1 \\
\hline CU.1972 & 1 & 1 & DH.4 & 1 & 1 \\
\hline CU.1983 & 1 & 1 & & & \\
\hline
\end{tabular}


Tabla 8. Evaluación de los marcadores moleculares asociados con el gen de resistencia $C k$ - 1 en los componentes de las variedades Castillo ${ }^{\circledR}$ regionales. La calificación binaria 1 indica la presencia de la forma alélica asociada con resistencia en forma homocigótica, 0 homocigoto para alelo asociado con susceptibilidad y $1 / 0$ la presencia simultánea de las formas alélicas asociadas a resistencia y susceptibilidad (heterocigotos).

\begin{tabular}{|c|c|c|c|c|c|c|c|c|c|}
\hline Línea & 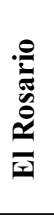 & 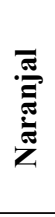 & 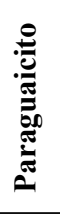 & 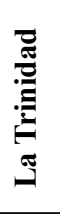 & $\begin{array}{l}\stackrel{0}{\bar{D}} \\
\text { 量 } \\
\stackrel{0}{0} \\
\stackrel{0}{\Xi}\end{array}$ & 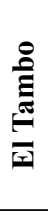 & 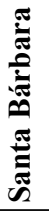 & SAT235 & FR34.6CTG \\
\hline BG.0459 & & & & $\mathrm{X}$ & & & & 1 & 1 \\
\hline BH.1247 & $\mathrm{X}$ & & $\mathrm{X}$ & & & & $\mathrm{X}$ & 1 & 1 \\
\hline BI.0712 & & & $\mathrm{X}$ & & & & & 1 & 1 \\
\hline CU.1778 & $\mathrm{X}$ & & & & & & $\mathrm{X}$ & 1 & 1 \\
\hline CU.1812 & $\mathrm{X}$ & $\mathrm{X}$ & $\mathrm{X}$ & $\mathrm{X}$ & & & $\mathrm{X}$ & 1 & 1 \\
\hline CU.1815 & $\mathrm{X}$ & & $\mathrm{X}$ & $\mathrm{X}$ & & $\mathrm{X}$ & $\mathrm{X}$ & 1 & 1 \\
\hline CU.1825 & $\mathrm{X}$ & & & & & & $\mathrm{X}$ & 1 & 1 \\
\hline CU.1827 & & $\mathrm{X}$ & & & & $\mathrm{X}$ & & 1 & 1 \\
\hline CU.1842 & & $\mathrm{X}$ & & & & & & 1 & 1 \\
\hline CU.1843 & & & $X$ & & & $X$ & & 1 & 1 \\
\hline CU.1852 & & & & & & $\mathrm{X}$ & & $1 / 0$ & 0 \\
\hline CU.1855 & & $\mathrm{X}$ & & & $\mathrm{X}$ & $X$ & & $1 / 0$ & 0 \\
\hline CU.1911 & & & $X$ & & & & & $1 / 0$ & 1 \\
\hline CU.1928 & & & $X$ & & & & & 1 & 1 \\
\hline CU.1970 & & $\mathrm{X}$ & & & & & & 1 & 1 \\
\hline CU.1997 & $\mathrm{X}$ & $\mathrm{X}$ & & & & & & 1 & 1 \\
\hline CU.2021 & & & $X$ & & & & $X$ & 1 & 1 \\
\hline CU.2034 & $\mathrm{X}$ & & & & & & & 1 & 1 \\
\hline
\end{tabular}

Continúa... 
...continuación.

\begin{tabular}{|c|c|c|c|c|c|c|c|c|c|}
\hline Línea & 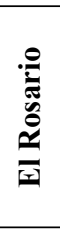 & 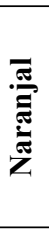 & 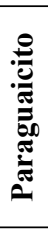 & 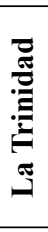 & 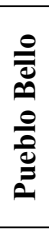 & 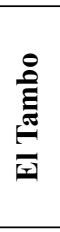 & 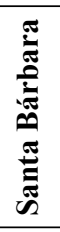 & SAT235 & FR34.6CTG \\
\hline CX.2065 & & & & & & $\mathrm{X}$ & & 1 & 1 \\
\hline CX.2074 & $\mathrm{X}$ & & $X$ & & & & & 1 & 1 \\
\hline CX.2178 & $\mathrm{X}$ & $\mathrm{X}$ & & & $\mathrm{X}$ & $\mathrm{X}$ & & 1 & 1 \\
\hline CX.2197 & & & $\mathrm{X}$ & & & $\mathrm{X}$ & & 1 & 1 \\
\hline CX.2385 & & $\mathrm{X}$ & & & & & & 1 & 1 \\
\hline CX.2391 & & & $\mathrm{X}$ & & & & & 1 & 1 \\
\hline CX.2710 & & $\mathrm{X}$ & & & $\mathrm{X}$ & & & 1 & 1 \\
\hline CX.2720 & & $X$ & & & & & & 1 & 1 \\
\hline CX.2827 & $\mathrm{X}$ & & & & & & & $1 / 0$ & 0 \\
\hline CX.2848 & $\mathrm{X}$ & $X$ & & & $\mathrm{X}$ & & & $1 / 0$ & 0 \\
\hline CX.2866 & & & & $\mathrm{X}$ & & & & 1 & 0 \\
\hline
\end{tabular}

Tabla 9. Evaluación de los marcadores moleculares asociados con el gen de resistencia $C k-1$ en los componentes de la variedad Cenicafé-1. La calificación binaria 1 denota la presencia de la forma alélica asociada con resistencia en forma homocigótica, 0 homocigoto para alelo asociado con susceptibilidad y 1/0 la presencia simultánea de las formas alélicas asociadas a resistencia y susceptibilidad (heterocigotos).

\begin{tabular}{cccc}
\hline Línea & SAT235 & & FR34.6CTG \\
\cline { 3 - 3 } CU.1819 & 1 & 1 \\
CU.1825 & 1 & 1 \\
CU.1849 & 1 & 1 \\
CU.1953 & 1 & 1 \\
CU.1993 & 1 & 1 \\
CU.2021 & 1 & 1 \\
CU.2034 & 1 & 1 \\
CX.2866 & 1 & 0 \\
\hline
\end{tabular}


Tabla 10.Evaluación de los marcadores moleculares asociados con el gen de resistencia $C k-1$ en los componentes de las variedades Castillo ${ }^{\circledR}$ Zonales. La calificación binaria 1 denota la presencia de la forma alélica asociada con resistencia en forma homocigótica, 0 homocigoto para alelo asociado con susceptibilidad y 1/0 la presencia simultánea de las formas alélicas asociadas a resistencia y susceptibilidad (heterocigotos).

\begin{tabular}{|c|c|c|c|c|c|}
\hline Línea & Castillo® Norte & Castillo ${ }^{\circledR}$ Centro & Castillo ${ }^{\circledR}$ Sur & SAT235 & FR34.6CTG \\
\hline ВН.1247 & & $\mathrm{X}$ & & 1 & 1 \\
\hline DH.0018 & $\mathrm{X}$ & $\mathrm{X}$ & $\mathrm{X}$ & 1 & 1 \\
\hline DH.0004 & $\mathrm{X}$ & & & 1 & 1 \\
\hline CU.1852 & & & $\mathrm{X}$ & $1 / 0$ & 0 \\
\hline CU.1855 & $\mathrm{X}$ & $\mathrm{X}$ & $\mathrm{X}$ & $1 / 0$ & 0 \\
\hline CU.1871 & $\mathrm{X}$ & $\mathrm{X}$ & $\mathrm{X}$ & $1 / 0$ & 0 \\
\hline CX.2710 & & & $\mathrm{X}$ & 1 & 1 \\
\hline CX.2720 & & & $\mathrm{X}$ & 1 & 1 \\
\hline CX.2633 & $\mathrm{X}$ & & & 1 & 1 \\
\hline CU.1951 & $\mathrm{X}$ & $\mathrm{X}$ & $\mathrm{X}$ & 1 & 1 \\
\hline CX.2385 & & $\mathrm{X}$ & & 1 & 1 \\
\hline CX.2391 & $\mathrm{X}$ & & & 1 & 1 \\
\hline CX.2178 & $\mathrm{X}$ & $\mathrm{X}$ & & 1 & 1 \\
\hline CX.2065 & $\mathrm{X}$ & & & 1 & 1 \\
\hline CX.2080 & $\mathrm{X}$ & $\mathrm{X}$ & $\mathrm{X}$ & 1 & 1 \\
\hline CU.1827 & & $\mathrm{X}$ & $\mathrm{X}$ & 1 & 1 \\
\hline CU.1778 & & $\mathrm{X}$ & & 1 & 1 \\
\hline CU.1842 & & $\mathrm{X}$ & & 1 & 1 \\
\hline CU.1843 & & & $\mathrm{X}$ & 1 & 1 \\
\hline CU.1850 & $\mathrm{X}$ & & $\mathrm{X}$ & 1 & 1 \\
\hline
\end{tabular}




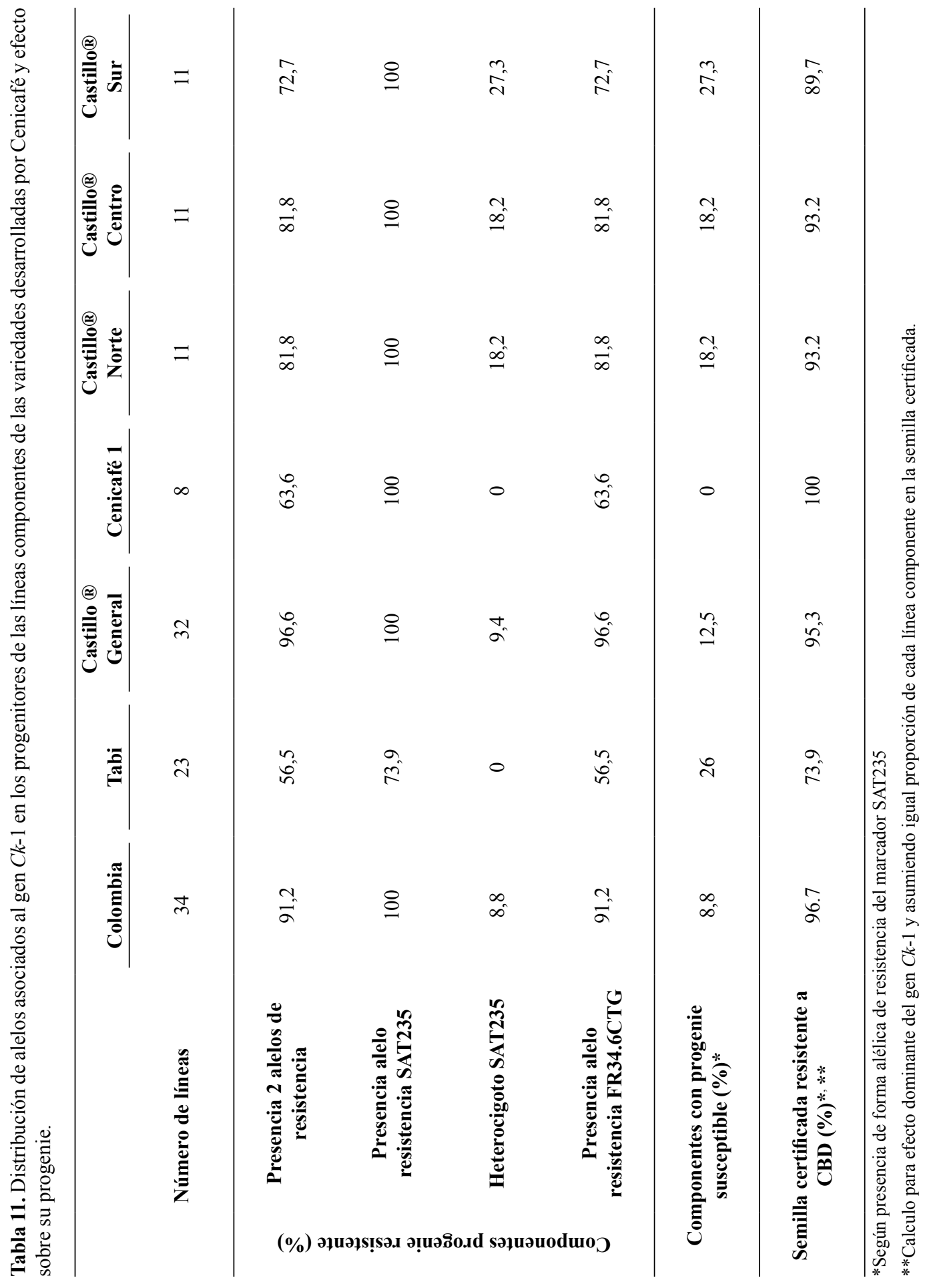




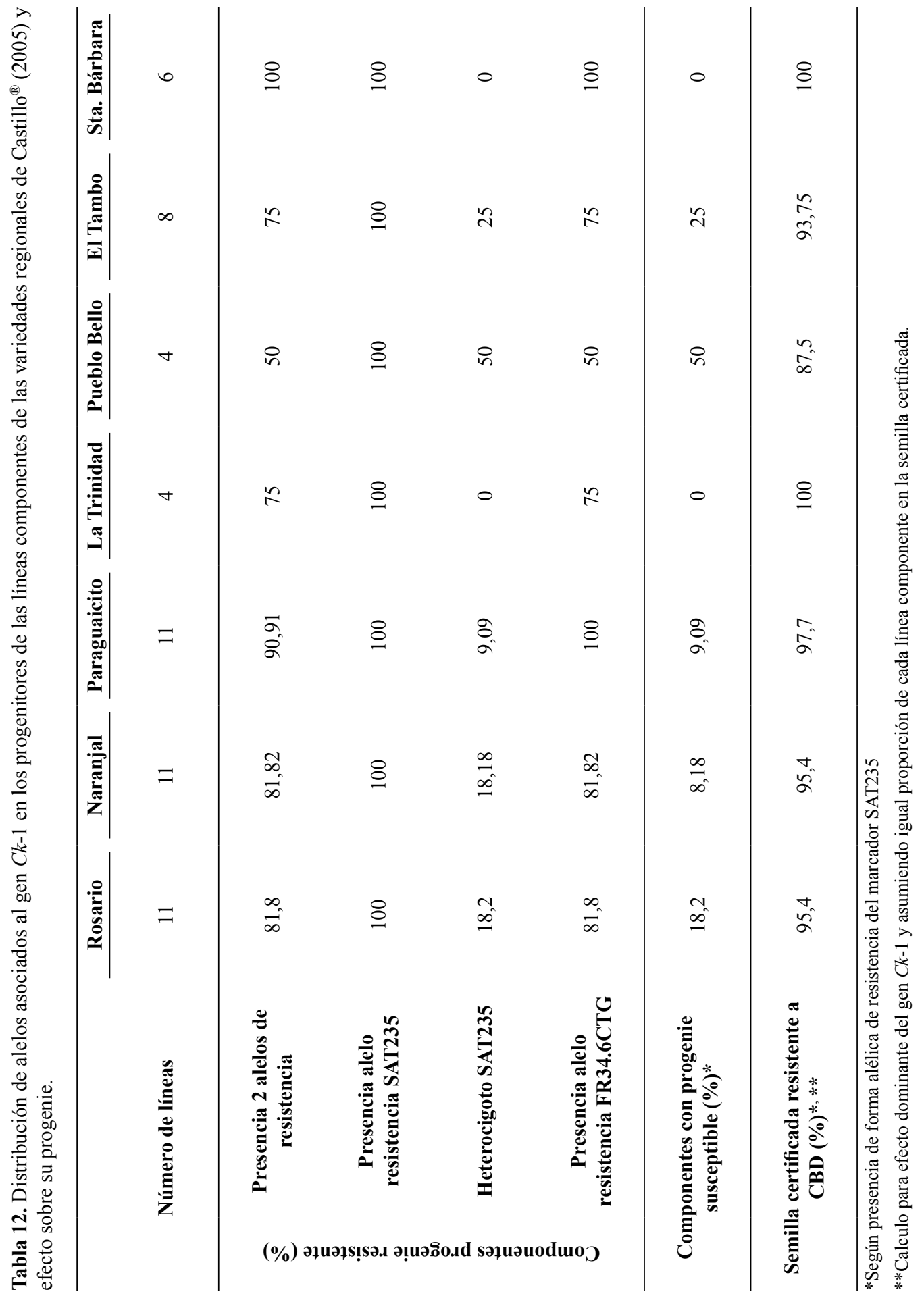


La diferencia de frecuencias de las formas alélicas de los marcadores SSRs asociados a la resistencia, evaluados para las variedades liberadas por Cenicafé, sugiere que hubo mayor presión de selección en favor del bloque de recombinación que contiene a SAT235 (que cosegrega con $C k$-1) en el programa de selección por resistencia a la roya del cafeto, que sobre el que contenía FR34-6CTG, lo que sugiere además la presencia de un gen de resistencia a roya derivado del HT en dicho bloque de recombinación, que puede corresponder a los genes SH6, SH7, SH8, SH9 o SH?, en un proceso genético conocido como arrastre genético por ligamiento, hipótesis que debe ser comprobada experimentalmente. Los estudios previos sugieren la cercanía de los factores de resistencia al marcador SAT235 y evidencian la ocurrencia de recombinación entre él y FR34-6CTG ya que se encuentran a una distancia de 17,2 cM (Gichuru et al., 2008). Esto también fue descrito por Alkimim et al. (2017) evaluando poblaciones derivadas de cruzamientos con HT. Este hallazgo demuestra la importancia de contar con marcadores moleculares estrechamente ligados al gen de interés para disminuir los errores de selección en programas apoyados por el análisis de marcadores moleculares como medida indirecta del fenotipo.

A pesar de que para algunos componentes de las líneas varietales el bloque introgresado que contiene el gen $C k-1$ no se había fijado en la generación $\mathrm{F} 4$, la estrategia de variedades multilínea desarrolladas por Cenicafé, hace que la población en general esté protegida teniendo desde $73,9 \%$ de plantas resistentes a CBD en cultivos comerciales de variedad Tabi hasta el $100 \%$ de las plantas resistentes con Cenicafé 1. Dado que, actualmente la resistencia a la enfermedad se basa en la presencia de un solo gen de efecto mayor es probable que la resistencia al CBD conferida por HT sea oligogénica (Van der Vossen \&
Walyaro, 1980, 2009) y que la estrategia de diversidad genética dentro de las variedades multilínea permita distribución de otros factores que contribuyan a la resistencia. Adicionalmente el Programa de Mejoramiento Genético de Cenicafé está desarrollando líneas que contengan o piramidicen los genes de resistencia $R$ y $k$ presentes en las variedades Rume Sudan y Pretoria (Van der Vossen \& Walyaro, 1980), para los que deben ser desarrollados marcadores moleculares para su detección e incorporación al programa de SAM de Cenicafé.

\section{Relación entre fenotipo y genotipo}

Al comparar la presencia de los marcadores moleculares con los registros de las pruebas de hipocótilos no se observó relación entre la presencia de los marcadores, sea en conjunto o de manera individual, con el patógeno o aislamiento específico (Tabla 13). La evaluación de las pruebas de infectividad mostró casos como el de la línea CU.1970, con los dos marcadores de resistencia para $C k-1$ y resistente a cinco aislamientos de nueve probados en ese material, y otros como el CU.1843 con presencia de los 2 marcadores de resistencia y susceptible a los 5 aislamientos probados. Según registros de Teferi (2014), de 13 variedades resistentes a CBD liberadas en Etiopía, cuatro (31\%) mostraron resistencia según la prueba de hipocótilo y también en el campo, mientras que siete (54\%) fueron susceptibles mediante la prueba de hipocótilo pero resistentes en el campo, lo cual soporta la baja confiabilidad de la prueba, con un alto número de falsos negativos cuando se evalúan materiales resistentes. Van der Vosen y Walyaro (2009) discuten una serie de inconvenientes de la prueba de hipocótilos y la necesidad de ser rigurosamente estandarizada para obtener información consistente con la resistencia en plantas adultas en el tiempo y el espacio (sitio de siembra). 
Tabla 13. Coeficiente de correlación Phi entre la presencia/ausencia de formas alélicas de resistencia de marcadores moleculares ligados a $C k-1$ y la resistencia/susceptibilidad a CBD mediante pruebas de hipocótilos.

\begin{tabular}{|c|c|c|c|c|c|c|c|c|c|}
\hline \multirow{3}{*}{ Marcador } & \multicolumn{9}{|c|}{ Aislamiento } \\
\hline & \multicolumn{2}{|c|}{ Camerún } & \multirow{2}{*}{$\frac{\text { Mozambique }}{\mathrm{M}}$} & \multicolumn{2}{|c|}{ Kenia } & \multirow{2}{*}{$\begin{array}{c}\text { Ruanda } \\
\mathbf{R}\end{array}$} & \multicolumn{3}{|c|}{ Zimbabue } \\
\hline & $\mathrm{C}$ & $\mathbf{C A}$ & & $\mathbf{Q}$ & Q2 & & $\mathbf{Z}$ & $\mathbf{Z 1}$ & Z9 \\
\hline SAT235 & $-0,202$ & $-0,303$ & 0,093 & $-0,034$ & $-0,085$ & $-0,058$ & $-0,091$ & 0,021 & 0,261 \\
\hline FR34-6CTG & 0,037 & $-0,167$ & 0,343 & 0,093 & 0,211 & $-0,058$ & $-0,014$ & 0,110 & 0,258 \\
\hline
\end{tabular}

El análisis de las pruebas de inoculación sobre variedad Caturra, como control susceptible en prueba ciega hecha por el CIFC, mostró que en el $98,35 \%$ de 182 pruebas, el genotipo fue reportado como susceptible y en el porcentaje restante describen variaciones de temperatura en la cámara de inoculación, que podrían estar relacionadas con el error de la prueba. Reportes de Van der Vossen y Waweru (1977) indican que en temperaturas superiores a $24^{\circ} \mathrm{C}$ los genotipos susceptibles mostraron infección reducida o nula, mientras que a temperaturas inferiores a $17^{\circ} \mathrm{C}$ genotipos de alta resistencia desarrollaron lesiones. Resultados similares son reportados por Vieira et al. (2019) quienes hallaron alta reproducibilidad de la prueba sobre hipocótilos y frutos desprendidos en variedad Caturra (CIFC 19/1).

La prueba de infectividad de hipocótilos no muestra alta reproducibilidad cuando se evalúan materiales resistentes. Se realizaron 12 pruebas de inoculación para el HT-1343-CV2, progenitor de las primeras liberaciones de la variedad Colombia, donde solo en el $66,66 \%$ de los casos el genotipo fue registrado como resistente. Aun si se evalúan semillas derivadas de un genotipo heterocigótico portador de un gen dominante, una prueba consistente calificaría en la mayoría de los casos como resistente al genotipo que segregue en relación 3:1 para fenotipos resistentes y susceptibles, respectivamente. Cabe anotar que el HT-
1343-CV2 es el progenitor de Catimor 88, material utilizado como fuente de resistencia para mapear el gen $C k-1$ (Gichuru et al., 2008), y también progenitor de otros materiales que fueron desarrollados en Cenicafé, los cuales han sido utilizados en programas de mejoramiento del café en Kenia, Tanzania y Zambia, como fuente de porte bajo y resistencia conjunta a CBD y a la roya (Mtenga et al., 2006; Kilambo et al., 2013a y 2013b; Gichuru, 2007; Omondi et al., 2001; Silva et al., 2006). Estas diferencias en la reproducibilidad de la prueba de infectividad soportan la discusión de Van der Vosen y Walyaro (2009) acerca de la necesidad de una rigurosa estandarización de la técnica, cuyos resultados son cruciales para el desarrollo de variedades resistentes a CBD en ausencia del patógeno.

Los resultados de este trabajo muestran el potencial de los estudios en genómica estructural y comparativa, que asociados con el mapeo de genes puede proveer herramientas para avanzar de forma rápida y precisa en el desarrollo de variedades de café. Adicionalmente los resultados obtenidos por los programas de mejoramiento en África, utilizando materiales desarrollados por Cenicafé, han demostrado la durabilidad de la resistencia a CBD proveniente de genes ubicados en regiones de introgresión heredadas del HT. Los resultados de este trabajo sugieren que la caficultura colombiana, con las variedades resistentes desarrolladas por 
Cenicafé y puestas al alcance de los caficultores, se encuentra preparada ante la eventual llegada de C. kahawae subsp. kahawae al país, ya que para el 2018 cerca del $80 \%$ del café plantado en el país corresponde a las variedades Colombia, Tabi y Castillo ${ }^{\circledR}$ y continuará en aumento con las nuevas variedades Cenicafé 1 y Castillo $^{\circledR}$ Zonales.

\section{AGRADECIMIENTOS}

Agradecemos a Jairo Jaramillo, Jhon Esteban Quintero y Carlos Augusto Vera por su colaboración en el desarrollo del trabajo, a Rubén Medina por la revisión de pruebas estadísticas, a Gustavo A. Marín por su asesoría en construcción de gráficas usando el programa $\mathrm{R}$ y a Beatriz Padilla por su ayuda en la corrección del texto.

\section{LITERATURA CITADA}

Alworah, G. O., (2019, abril 27). Mummified berries due to $C B D$ infection, Over $80 \%$ crop loss. https://nextgen. iupac2019.be/2019/02/26/development-and-promotionof-biological-control-approaches-for-management-ofcoffee-berry-disease/

Alkimim, E. R., Caixeta, E. T., Sousa, T. V., Pereira, A. A., Oliveira, A. C. B., Zambolim, L., \& Sakiyama, N. S. (2017). Marker-assisted selection provides arabica coffee with genes from other Coffea species targeting on multiple resistance to rust and coffee berry disease. Molecular Breeding, 37(1), 6. https://doi.org/10.1007/ s11032-016-0609-1

Alvarado, G., Posada, H. E., \& Cortina, H. A. (2005a). Castillo $^{\circledR}$ : Nueva variedad de café con resistencia a la roya. Avances Técnicos Cenicafé, 337, 1-8. http://hdl. handle.net/10778/401

Alvarado, G., Posada, H. E., Cortina, H. A., Duque, H., Baldión, J. V., \& Guzmán, O. (2005b). La Variedad Castillo $^{\circledR}$ Pueblo Bello para las regiones cafeteras de Magdalena, Cesar, La Guajira y Norte de Santander. Avances Técnicos Cenicafé, 341, 1-8. http://hdl.handle. net/10778/342
Alvarado, G., Posada, H. E., Cortina, H. A., Duque, H., Baldión, J. V., \& Guzmán, O. (2005c). La Variedad Castillo ${ }^{\circledR}$ Santa Bárbara para las regiones cafeteras de Cundinamarca y Boyacá. Avances Técnicos Cenicafé, 342, 1-8. http://hdl.handle.net/10778/383

Alvarado, G., Posada, H. E., Cortina, H. A., Duque, H., Baldión, J. V., \& Guzmán, O. (2005d) La Variedad Castillo ${ }^{\circledR}$ La Trinidad para las regiones cafeteras del Tolima. Avances Técnicos Cenicafé, 343, 1-8. http:// hdl.handle.net/10778/348

Alvarado, G., Posada, H. E., Cortina, H. A., Duque, H., Baldión, J. V., \& Guzmán, O. (2006a). La Variedad Castillo ${ }^{\mathbb{R}}$ Naranjal para las regiones cafeteras de Caldas, Quindío, Risaralda y Valle del Cauca.Avances Técnicos Cenicafé, 338, 1-8. http://hdl.handle.net/10778/413

Alvarado, G., Posada, H. E., Cortina, H. A., Duque, H., Baldión, J. V., \& Guzmán, O. (2006b). La Variedad Castillo ${ }^{\circledR}$ Paraguaicito para las regiones cafeteras de Quindío, Risaralda y Valle del Cauca.Avances Técnicos Cenicafé, 339, 1-8. http://hdl.handle.net/10778/417

Alvarado A., G., Posada S., H. E., Cortina G., H. A., Duque O., H, Baldión R., J. V. \& Guzmán M., O. (2006c). La Variedad Castillo ${ }^{\circledR}$ El Rosario para las regiones cafeteras de Antioquia, Risaralda y Caldas. Avances Técnicos Cenicafé, 340, 1-8. http://hdl.handle.net/10778/403

Ashburner, M., Ball, C. A., Blake, J. A., Botstein, D., Butler, H., Cherry, J. M., Davis, A. P., Dolinski, K., Dwight, S. S., Eppig, J. T., Harris, M. A., Hill, D. P., Issel-Tarver, L., Kasarskis, A., Lewis, S., Matese, J. C., Richardson, J. E., Ringwald, M., Rubin, G. M., \& Sherlock, G. (2000). Gene ontology: tool for the unification of biology. Nature genetics, 25(1), 25-29. https://doi.org/10.1038/75556

Castillo Z., J., \& Moreno R., L. G. (1988). La variedad Colombia: Selección de un material compuestoresistente a la roya del cafeto. Cenicafé.

Clarindo, W. R., Carvalho, C. R., Caixeta, E. T., \& Koehler, A. D. (2013). Following the track of "Híbrido de Timor" origin by cytogenetic and flow cytometry approaches. Genetic Resources and Crop Evolution, 60(8), 22532259. https://doi.org/10.1007/s10722-013-9990-3

Cook, R. T.A., \& Van der Vossen, H.A. M. (1972). Screening coffee plants for CBD resistance. Annual Report Coffee Research Foundation, Kenya, 73, 66-68.

Denoeud, F., Carretero-Paulet, L., Dereeper, A., Droc, G., Guyot, R., Pietrella, M., Zheng, C., Alberti,A., Anthony, F., Aprea, G., Aury, J.-M., Bento, P., Bernard, M., Bocs, S., Campa, C., Cenci, A., Combes, M.-C., Crouzillat, 
D., Da Silva, C., ... Lashermes, P. (2014). The coffee genome provides insight into the convergent evolution of caffeine biosynthesis. Science, 345(6201), 1181-1184. https://doi.org/10.1126/science.1255274

Flórez, C. P., Maldonado, C. E., Cortina, H. A., Moncada, M. P., Montoya, E. C., Ibarra, L. N., Unigarro, C. A., Rendón, J. R., \& Duque, H. (2016). Cenicafé 1 nueva variedad de porte bajo, altamente productiva, resistente a la roya y al CBD, con mayor calidad física del grano. Avances Técnicos Cenicafé, 469, 1-8. http://hdl.handle. net/10778/1114

Flórez, C. P., Arias, J. C., Maldonado, C. E., Cortina, H.A., Moncada, M. P., Quiroga, J., Molina, D. M., García, J. C., \& Duque, H. (2018). Variedades Castillo ${ }^{\circledR}$ Zonales: resistencia a la roya con mayor productividad. Avances Técnicos Cenicafé, 489, 1-8. http://hdl.handle. net/10778/1115

The Gene Ontology Consortium. (2019). The gene ontology resource: 20 years and still GOing strong. Nucleic Acids Research,47(D1), D330-D338.https://doi.org/10.1093/ nar/gky1055

Gichimu, B. M., Gichuru, E. K., Mamati, G. E., \& Nyende,A. B. (2014). Occurrence of $C k$-1 gene conferring resistance to Coffee Berry Disease in Coffea arabica cv. Ruiru 11 and its parental genotypes. Journal of Agricultural and Crop Research, 2(3), 51-61.

Gichuru, E. K. (2007). Characterization of genetic resistance to Coffee Berry Disease (Colletotrichum kahawae Waller and Bridge) in Arabica coffee (Coffea arabica L.) that is introgressed from Coffea canephora Pierre. [Unpublished doctoral dissertation]. University of Nairobi.

Gichuru, E. K., Agwanda, C. O., Combes, M. C., Mutitu, E. W., Ngugi, E. C. K., Bertrand, B., \& Lashermes, P. (2008). Identification of molecular markers linked to a gene conferring resistance to coffee berry disease (Colletotrichum kahawae) in Coffea arabica. Plant pathology, 57(6), 1117-1124. https://doi.org/10.1111/ j.1365-3059.2008.01846.x

Griffiths, E., Gibbs, J. N., \& Waller, J. M. (1971). Control of coffee berry disease. Annals of Applied Biology, 67(1),45-74.https://doi.org/10.1111/j.1744-7348.1971. tb02907.x

Guzmán, F.A.,\& Moncada-Botero, M.(2012). Evaluación de marcadores SSR ligados a resistencia a Colletotrichum kahawae en Coffea arabica. Revista Cenicafé, 63(2), 7-22. http://hdl.handle.net/10778/532
Kilambo, D. L., Reuben, S. O., \& Mamiro, D. (2013a). Races of Hemileia vastatrix and variation in pathogenicity of colletotrichum kahawae isolates to compact coffee genotypes in Tanzania. Journal of Plant Studies, 2(2), 95-104. http://www.suaire.suanet.ac.tz:8080/xmlui/ handle/123456789/1304

Kilambo, D. L., Reuben, S. O., \& Mamiro, D. P. (2013b). Responses of Compact Coffee Clones Against Coffee Berry and Coffee Leaf Rust Diseases in Tanzania. Journal of Plant Studies, 2(2), 81-94. http://www. suaire.suanet.ac.tz:8080/xmlui/handle/123456789/1422

Lashermes, P., Combes, M. C., Ribas, A., Cenci,A., Mahé, L., \& Etienne, H. (2010). Genetic and physical mapping of the $\mathrm{SH} 3$ region that confers resistance to leaf rust in coffee tree (Coffea arabica L.). Tree Genetics \& Genomes, 6(6), 973-980. https://doi.org/10.1007/s11295-010-0306-x

Moncada, M. D. P., Tovar, E., Montoya, J. C., González, A., Spindel, J., \& McCouch, S. (2015). A genetic linkage map of coffee (Coffea arabica L.) and QTL for yield, plant height, and bean size. Tree Genetics \& Genomes, 12(1), 1-17.https://doi.org/10.1007/s11295-015-0927-1

Mtenga, D.J., Kilambo, D.L., Teri, J.M., \& Masumbuko, L. (2006, september 10-15). Progress in developing Coffee Berry Disease (Colletotrichum kahawae) resistant compact hybrid varieties (Coffea arabica) in Tanzania [Conference session]. 21 ${ }^{\text {st }}$ International Scientific Colloquium on Coffee, Montpellier, France. https:// www.asic-cafe.org/conference/21st-internationalscientific-colloquium-coffee/progress-developingcoffee-berry-disease

Mugo, H. M., Irungu, L. W., \& Ndegwa, P. N. (2012). The diseases of coffee under the changing climate: The established situation in Kenya. Journal of Agricultural Science and Technology, 2(2A), 265-267.

Omondi, C. O., Ayiecho, P. O., Mwang'ombe, A. W., \& Hindorf, H. (2001). Resistance of Coffea arabica cv. Ruiru 11 tested with different isolates of Colletotrichum kahawae, the causal agent of coffee berry disease. Euphytica, 121(1), 19-24. https://doi. org/10.1023/A:1012056622969

Phiri, N. (2018). Colletotrichum kahawae. Centre for Agriculture and Bioscience International-CABI.https:// www.plantwise.org/knowledgebank/datasheet/14916/

Posada, H. E., Alvarado, G., Cortina, H. A., Solarte, C. R., Duque, H., Baldión, J. V., \& Guzmán, O. (2006). La Variedad Castillo ${ }^{\circledR}$ El Tambo: para las regiones cafeteras de Cauca, Nariño, Huila, Tolima y Valle del Cauca. 
Avances Técnicos Cenicafé, 344, 1-8. http://hdl.handle. net $/ 10778 / 390$

Schuler, G. D. (1997). Sequence mapping by electronic PCR. Genome Research, 7(5), 541-550. https://doi. org/10.1101/gr.7.5.541

Silva, M. D. C., Várzea, V., Guerra-Guimarães, L., Azinheira, H. G., Fernandez, D., Petitot, A. S., Bertrand, B., Lashermes, P., \& Nicole, M. (2006). Coffee resistance to the main diseases: leaf rust and coffee berry disease. Brazilian Journal of Plant Physiology, 18(1), 119-147. https://doi.org/10.1590/ S1677-04202006000100010

Teferi, D. (2014). Status of released Coffea arabica varities for their resistance to Colletotrichum kahawae (coffee berry disease) under laboratory condition. Discourse Journal of Agriculture and Food Sciences, 2(6), 197-202. http:// www.resjournals.org/JAFS/PDF/2014/Jun/Teferi.pdf

Van der Graaff, N. A. (1981). Selection of arabica coffee types resistant to coffee berry disease in Ethiopia. [Unpublished doctoral dissertation]. Agricultural University of Wageningen.

Van Der Vossen, H. A. M. \& Walyaro, D. J. (1980) Breeding for resistance to coffee berry disease in Coffea arabica $\mathrm{L}$. II. Inheritance of resistance. Euphytica, 29(3), 777-791. https://doi.org/10.1007/BF00023225
Van Der Vossen, H.A. M., \& Walyaro, D. J. (2009).Additional evidence for oligogenic inheritance of durable host resistance to coffee berry disease (Colletotrichum kahawae) in arabica coffee (Coffea arabica L.). Euphytica, 165(1), 105-111. https://doi.org/10.1007/ s10681-008-9769-3

Van Der Vossen, H. A. M. \& Waweru J. M. (1977). A temperature controlled inoculation room to increase efficiency of preselection for resistance to coffee berry disease. Kenya Coffee, 41, 164-167.

Vieira, A., Diniz, I., Loureiro, A., Pereira, A. P., Silva, M. C., Várzea, V., \& Batista, D. (2019). Aggressiveness profiling of the coffee pathogen Colletotrichum kahawae. Plant pathology, 68(2),358-368.https://doi.org/10.1111/ ppa. 12950

Yang, S., Zhang, X., Yue, J. X., Tian, D., \& Chen, J. Q. (2008). Recent duplications dominate NBS-encoding gene expansion in two woody species. Molecular Genetics and Genomics, 280(3), 187-198. https://doi. org/10.1007/s00438-008-0355-0

Zhou, T., Wang, Y., Chen, J.Q., Araki, H., Jing, Z., Jiang, K., Shen, J., \& Tian, D. (2004). Genome-wide identification of NBS genes in japonica rice reveals significant expansion of divergent non-TIR NBS-LRR genes. Molecular Genetics and Genomics, 271(4), 402-415. https://doi.org/10.1007/s00438-004-0990-z 